\title{
Epithelial-mesenchymal transition triggers cancer stem cell generation in human thyroid cancer cells
}

\author{
LING LAN $^{1}$, YONG LUO ${ }^{2}$, DAI CUI $^{3}$, BING-YIN SHI $^{4}$, WEI DENG $^{1}$, LI-LI HUO ${ }^{1}$, \\ HAI-LING CHEN ${ }^{1}$, GUO-YING ZHANG ${ }^{1}$ and LI-LI DENG ${ }^{1}$ \\ ${ }^{1}$ Department of Endocrinology, Beijing Ji Shui Tan Hospital, The 4th Medical College of Peking University; \\ ${ }^{2}$ Department of Urology, Affiliated Beijing Anzhen Hospital of Capital Medical University, Beijing; \\ ${ }^{3}$ Department of Endocrinology, First Affiliated Hospital of Nanjing Medical University, Nanjing; \\ ${ }^{4}$ Department of Endocrinology, The First Affiliated Hospital of Medical College of \\ Xi'an Jiaotong University, Xi'an, P.R. China
}

Received January 26, 2013; Accepted March 14, 2013

DOI: $10.3892 /$ ijo.2013.1913

\begin{abstract}
Increasing evidence has shown that cancer stem cells or tumor initiating cells are the 'root cause' of malignant cancers. However, the exact origin of cancer stem cells still remains obscure in thyroid research. EMT has been implicated in the initiation and conversion of early-stage tumors into invasive malignancies and is associated with the stemness of cancer cells. Based on these facts, a new hypothesis was suggested that EMT induces cancer stem cell generation and tumor progression in human thyroid cancer cells in vitro. In the present study, FTC133 cells identified as EMT-negative cells were used for EMT induction by HIF-1 $\alpha$ transfection. Overexpression of HIF-1 $\alpha$ induced FTC133 cells to undergo EMT, downregulated the epithelial markers E-cadherin, upregulated the mesenchymal marker vimentin, and associated with highly invasive and metastatic properties. Most importantly, the induction of EMT promoted the stem-like side population cell proportion in the FTC133 cells. These results indicate that EMT induction promotes CSC traits and cell proportions in the thyroid cancer cells, which implies that EMT could induce cancer stem cell generation and tumor progression in thyroid cancers. Further understanding of the role of EMT and cancer stem cells in cancer progression may reveal new targets for the prevention or therapy of thyroid cancers.
\end{abstract}

\section{Introduction}

Anaplastic thyroid carcinoma is an aggressive malignancy characterized by an extensive local invasion, early systemic

Correspondence to: Dr Ling Lan, Department of Endocrinology, Beijing Ji Shui Tan Hospital, The 4th Medical College of Peking University, Xi Chen Qu Xin Jie Kou Dong Jie 31, Beijing 100035, P.R. China

E-mail: lanjingling0627@hotmail.com

Key words: hypoxic inducible factor $1 \alpha$, thyroid, cancer stem cell, epithelial-mesenchymal transition dissemination and marked resistance to chemo- and radiotherapy, and always has a poor prognosis with a mean survival of only few months (1). Current systemic therapy fails to eradicate this cancer or even to stop tumor progress. It has been hypothesized that this may be explained by the failure of current drugs to effectively target cancer stem-like cells (CSCs) $(2,3)$. To date, CSCs have been reported in various solid tumors and in cancer cell lines (4-9). However, until recently, there are only very few studies on adult thyroid stem/progenitor cells and thyroid CSCs (10-12). We and others have recently described and characterized thyroid cancer stem cells as a side population (13-17) that may play a critical role in the progression and recurrence of cancer and its subsequent metastasis (18).

Epithelial to mesenchymal transition (EMT) is a vital process for morphogenesis during embryonic development, but it has also been implicated in the conversion of early stage tumors into invasive malignancies (19). More recent studies have further demonstrated that EMT plays a critical role not only in tumor metastasis but also in tumor recurrence that is believed to be tightly linked with the biology of cancer stem-like cells or cancer-initiating cells (20-23). The relationship between EMT and CSCs has been observed, with the evidence suggesting that EMT cells acquire stem cell-like traits and that CSCs exhibit a mesenchymal-like appearance in immortalized non-tumorigenic mammary epithelial cells and breast cancers (22). In thyroid cancer, it was found in our previous study that cancer stem cell content was associated with EMT-phenotype, e.g. mesenchymal-type cells of HTH74 was detected with a much bigger cancer stem-like cell population than epithelial-type cells of FTC133. With these findings in mind, we proposed a plausible hypothesis that EMT program induces the generation of thyroid cancer stem cells.

To test the hypothesis we performed EMT induction through HIF-1 $\alpha$ cDNA transfection on EMT-negative thyroid cancer cells, and found that HIF-1 $\alpha$-overexpressed FTC133 cells acquired EMT phenotype and shared stem-like cell features. Most importantly, EMT induction was directly associated with increased stem-like cell population. These data suggest that EMT represent the vital impetus of cancer stem cell generation 
and thus prompt tumor progression and metastasis, and these findings may provide useful perspectives for anticancer drug exploitation in containment of thyroid CSC generation.

\section{Materials and methods}

Cell culture. The human thyroid carcinoma cell line FTC133 was kindly provided by Professor M. Derwahl, Humboldt University, Germany. The FTC133 cell line was derived from the primary tumor of a 42-year-old male patient with metastatic thyroid follicular carcinoma (24), and then cultured in Dulbecco's modified Eagle's medium (DMEM) supplemented with $10 \%$ fetal bovine serum and penicillin/streptomycin in a humidified incubator at $37^{\circ} \mathrm{C}$ and $5 \% \mathrm{CO}_{2}$.

Plasmids and transfections. Recombinant plasmid pcDNA3.1(-)/HIF-1 $\alpha$ was kindly provided by Dr Luo, Affiliated Beijing Anzhen Hospital of Capital Medical University, China. For EMT induction, EMT-negative (epithelial-type) FTC133 cells were transfected with pcDNA3.1(-)/HIF-1 $\alpha$ with Lipofectamine 2000 system (Invitrogen). After $24 \mathrm{~h}$ of transient transfection, cells were subsequently cultured in medium containing $600 \mu \mathrm{g} / \mathrm{ml}$ of G418 for 4 weeks. HIF-1 $\alpha$ positive cell clones were selected and expanded. FTC133 cells stably transfected with HIF-1 $\alpha$ were designated as FTC133/HIF-1 $\alpha$. After transfection, cells were maintained in hypoxic environment (under $1 \%$ oxygen) for further culture and experiments.

Western blot analysis. Antibodies against HIF-1 $\alpha$ (as an EMT inducer), Glut-1, VEGF (as HIF-1 $\alpha$ target proteins), E-cadherin, CK18 (as epithelial proteins), fibronectin, vimentin (as mesenchymal markers), $\beta$-actin (as an internal control) were used for western blot analyses as per instructions from manufacturers. Cell lysate preparation and blotting conditions have been described previously (25).

Immunofluorescent staining. Cells were fixed in $10 \%$ paraformaldehyde for $30 \mathrm{~min}$ and blocked with goat serum for $30 \mathrm{~min}$, respectively. Cells were then incubated at $37^{\circ} \mathrm{C}$ for $1 \mathrm{~h}$ with rabbit anti-human $\beta$-catenin antibody (Santa Cruz Biotechnology) at a dilution of 1:100. After washing 3 times with PBS, cells were co-incubated with fluorescence isothiocyanate (FITC) conjugated goat anti-rabbit antibody at $37^{\circ} \mathrm{C}$ for $1 \mathrm{~h}$. DAPI was used for nuclear DNA staining. The fluorescence staining intensity and intracellular localization were then examined by Olympus immunofluorescence microscope.

Invasion assays. The cells were cultured in 6-well plates to $90 \%$ confluency and then collected after trypsinization. An analysis assessing the invasion of cells was performed using 6-well Transwell inserts with $6.5-\mathrm{mm}$ diameters and $8-\mu \mathrm{M}$ pores (Corning). In brief, the filters were precoated for $30 \mathrm{~min}$ at $37^{\circ} \mathrm{C}$ with $25 \mu$ l extracellular matrix (Sigma-Aldrich) gel mixed with dimethyl sulfoxide (1:1). The trypsinised cells $\left(7 \times 10^{4}\right)$ were washed with PBS, resuspended in the serum-free medium, and placed in the upper chamber, and a medium containing $10 \%$ FBS was used as a chemoattractant in the lower chamber. Cells were incubated at $37^{\circ} \mathrm{C}$ in $5 \% \mathrm{CO}_{2}$ for 24,48 and $72 \mathrm{~h}$, respectively, and the number of cells that invaded across the membranes were fixed and stained with Giemsa. The non-migratory cells on the upper chamber were removed with cotton swabs, and the migratory cells present on the lower surface were counted in 10 random fields and photographed by field at x100 magnification under an inverted microscope (Olympus).

MTT assay for cell proliferation. Cells $\left(1 \times 10^{4}\right)$ were split into each well of 96 -well tissue culture plates. At various time points $(1,2,3,4$ and 5 days), MTT solution $(2.5 \mathrm{mg} / \mathrm{ml} ; 50 \mu \mathrm{l})$ was added into the cell culture plate and incubated with cells for an additional $4 \mathrm{~h}$. The media were collected separately from each chamber, and cell-associated MTT crystals were dissolved separately in dimethyl sulfuroxide (DMSO, $150 \mu \mathrm{l} /$ well) on a shaker at room temperature. The color intensity was measured at $570 \mathrm{~nm}$ against the appropriate blank controls (0.1\% BSA/RPMI-1640 medium with MTT solution and $150 \mu 1$ DMSO) using a Bio-Rad Technologies Microplate Reader.

Spheroid formation assay. The potential of self-renewal was assessed using Corning Ultra-Low Attachment Surface (Corning). Cells suspension was sieved through a $30 \mu \mathrm{m}$ strainer, centrifuged and resuspended in growth factor-enriched medium: serum-free DMEM/Ham's F-12 (1:1) containing B-27 (1:50), 20 ng/ml EGF (Invitrogen, Karlsruhe, Germany), and $20 \mathrm{ng} / \mathrm{ml}$ bFGF (Invitrogen). Single cellularity was confirmed under a microscope. Cells were cultured in $100-\mathrm{mm}$ dishes at 10,000 viable cells $/ \mathrm{ml}$ at $37^{\circ} \mathrm{C}$, in $5 \% \mathrm{CO}_{2}$ culture incubator. Every 2-3 days, B27, bFGF and EGF were added. After 10 days of culturing, spheres in 10 independent microscopic fields were enumerated. The percentage of cells that initiated a sphere was presented as sphere-forming efficiency (CFE).

Colony-forming assays. Single-cell suspensions (200 cells per dish) were seeded on 60-mm dishes (Corning) and cultured for 14 days. The media were changed every 4 days. The colonies were washed twice with PBS, and counted under a microscope. Only colonies with $>32$ cells were scored. The percentage of cells that initiated a clone was presented as colony-forming efficiency (CFE).

SP sorting with FACS. Cells were harvested with Hoechst 33342 staining, and verapamil (Sigma, St. Louis, MO, USA), an inhibitor of ABCG2 transporter, was used to identify specific cell populations, as described previously (14). A $350-\mathrm{nm}$ UV laser was used to excite Hoechst 33342. Analysis was performed using a dual-wavelength analysis (blue, $420 \mathrm{~nm}$; red, $670 \mathrm{~nm}$ ). The side population was identified by gating on the characteristic fluorescence emission profile. Equal numbers of SP and non-SP (NSP) cells were collected for the following experiments.

RNA isolation and reverse transcription polymerase chain reaction (RT-PCR). Total RNA was extracted using the RNeasy Micro kit (Qiagen) according to the manufacturer's specifications. RT-PCR was performed as described previously (14). For PCR amplification, reactions were carried out at $95^{\circ} \mathrm{C}$ for $10 \mathrm{~min}, 25-30$ cycles of $95^{\circ} \mathrm{C}$ for $30 \mathrm{sec}, 52-59^{\circ} \mathrm{C}$ (primer specific) for $30 \mathrm{sec}$ and $72^{\circ} \mathrm{C}$ for $1 \mathrm{~min}$, followed by a final extension at $72^{\circ} \mathrm{C}$ for $10 \mathrm{~min}$ and termination at $4^{\circ} \mathrm{C}$. RT-PCR 
Table I. Primer sequences, annealing temperatures and product sizes for semi-quantitative RT-PCR.

\begin{tabular}{|c|c|c|c|}
\hline Target gene & Primer sequences $^{\mathrm{a}}$ & Annealing temperature $\left({ }^{\circ} \mathrm{C}\right)$ & Expected size (bp) \\
\hline \multirow[t]{2}{*}{ E-cadherin } & S: $\quad$ 5'-ctgaagtgactcgtaacgac-3' & & \\
\hline & AS: 5'-catgtcagccagcttcttgaag-3' & 55 & 300 \\
\hline \multirow[t]{2}{*}{ Vimentin } & S: 5'-tggcacgtcttgaccttgaa-3' & & \\
\hline & AS: 5'-ggtcatcgtgatgctgagaa-3' & 56 & 749 \\
\hline \multirow[t]{2}{*}{$\mathrm{ABCG} 2$} & S: $\quad$ '-agttccatggcactggccata-3' & & \\
\hline & AS: 5'-tcaggtaggcaattgtgagg-3' & 56 & 379 \\
\hline \multirow[t]{2}{*}{ OCT4 } & S: 5'-gacaacaatgagaaccttcaggag-3' & & \\
\hline & AS: 5'-ctggcgccggttacagaacca-3' & 56 & 216 \\
\hline \multirow[t]{2}{*}{ TG } & S: $\quad 5^{\prime}$-agtcctaagtcccctgatgc-3' & & \\
\hline & AS: 5'-caagggagacgtcgagtgt-3' & 52 & 280 \\
\hline \multirow[t]{2}{*}{ NIS } & 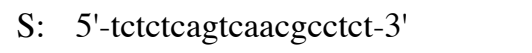 & & \\
\hline & AS: 5'-atccaggatggccacttctt-3' & 58 & 299 \\
\hline \multirow[t]{2}{*}{$\beta$-actin } & S: 5'-cccaggcaccagggcgtgat-3' & & \\
\hline & AS: 5'-tcaaacatgatctgggtcat-3' & 59 & 280 \\
\hline
\end{tabular}

${ }^{a} \mathrm{~S}$, sense primer; AS, antisense primer.

cycles varied between primer sets to ensure that amplification has not reached saturation level.

In all PCR analyses, $\beta$-actin was used as an internal control. Primer sequences, product sizes, and annealing temperatures are listed in Table I. The PCR products were separated by electrophoresis on $1.5 \%$ agarose gels stained with ethidium bromide. Signals corresponding to target gene expression were normalized relative to $\beta$-actin for each sample.

Statistical analysis. All data are represented as mean \pm SD from at least three independent experiments. When two groups were compared, the Student's t-test was used, and $\mathrm{p}<0.05$ was considered significant.

\section{Results}

Overexpression of HIF-1 $\alpha$ induces EMT and $\beta$-catenin nucleus translocation. HIF-1 $\alpha$ has been shown to induce EMT, during which epithelial cells lose their polarity and convert to a mesenchymal phenotype (25). In this study, we transfected FTC133 cells with vector encoding human HIF-1 $\alpha$. Six weeks later, the stable FTC133/HIF-1 $\alpha$ cell clones were obtained. Upon observation by microscopy, the FTC133/HIF-1 $\alpha$ cells showed typical fibroblast-like and spindle-shaped appearance, whereas the untransfected FTC133 cells showed robust cellular junctions with typical 'cobblestone-shaped' and epithelial-like appearance (Fig. 1B). To determine if the pattern of protein expression correlated with EMT, western blot analysis was performed. Functional expression of HIF-1 $\alpha$ was confirmed since two downstream target proteins, Glut-1 and VEGF, regulated by HIF-1 $\alpha$ were both positively expressed in FTC133/HIF-1 $\alpha$ cells. In addition, the increased expression of HIF-1 $\alpha$ resulted in a decrease of the epithelial markers E-cadherin and CK18, but an increase of vimentin and fibronectin (Fig. 1A). Moreover, as shown in immuno- fluorescent staining (Fig. 1B), HIF-1 $\alpha$ induction resulted in specific nucleus translocation of $\beta$-catenin from the cytoplasma. These results demonstrated that increased HIF-1 $\alpha$ expression prompted EMT induction and $\mathrm{Wnt} / \beta$-catenin signal activation in FTC133 cells.

Cells that acquire an EMT phenotype show high invasiveness and proliferation in vitro. To test whether the cells that have undergone EMT show changes in invasiveness and metastatic ability, transwell assay was performed to measure single-cell invasion. After different time points, the invasive cells were quantified and photographed at x100 magnification in 10 randomly chosen fields. The FTC133/HIF-1 $\alpha$ cells were more invasive than untransfected FTC133 cells and showed a 6-fold increase in gel invasion after 24-h incubation ( $p<0.01$, Fig. $2 \mathrm{~A}$ and B), which indicated that enhanced HIF-1 $\alpha$ expression contributes to increased invasiveness. Moreover, MTT proliferation assay displayed much higher proliferation in FTC133/HIF-1 $\alpha$ cells than untransfected FTC133 cells at each time-point (all $\mathrm{p}<0.05$ except time-point of 0 day, Fig. 2C). Specifically, doubling of FTC133/HIF-1 $\alpha$ cells occurs on day 2, whereas that of FTC133 cells occurs on day 5. This finding indicates cells that acquire an EMT phenotype were more invasive and proliferative in vitro.

EMT generates stem-like cells that express markers associated with both stemness and mesenchymal properties. To test the hypothesis that EMT program determines the CSC generation, stem-like side population cells were compared in FTC133 and FTC133/HIF-1 $\alpha$ cells. As depicted in Fig. 3A, through HIF-1 $\alpha$ transfection, FTC133 cells acquired a much bigger side population in contrast to untransfected cells (SP, 0.7 vs. $0.03 \%$ ). In our previous study side population cells from either thyroid primary tissue or anaplastic thyroid cancer cell lines were identified as primitive stem cells with associated 
A

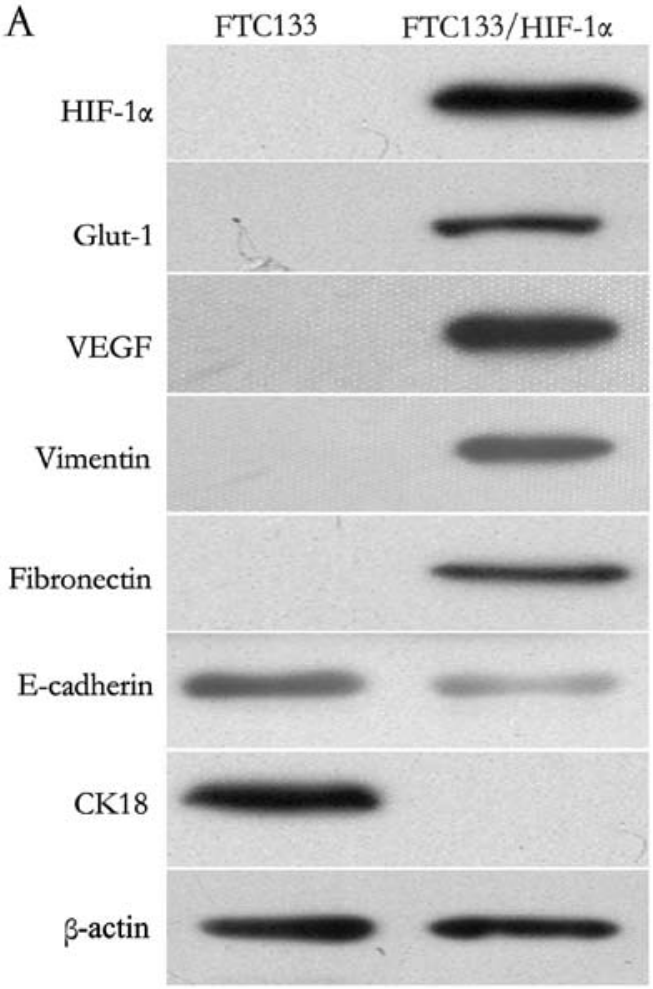

$\mathrm{B}$

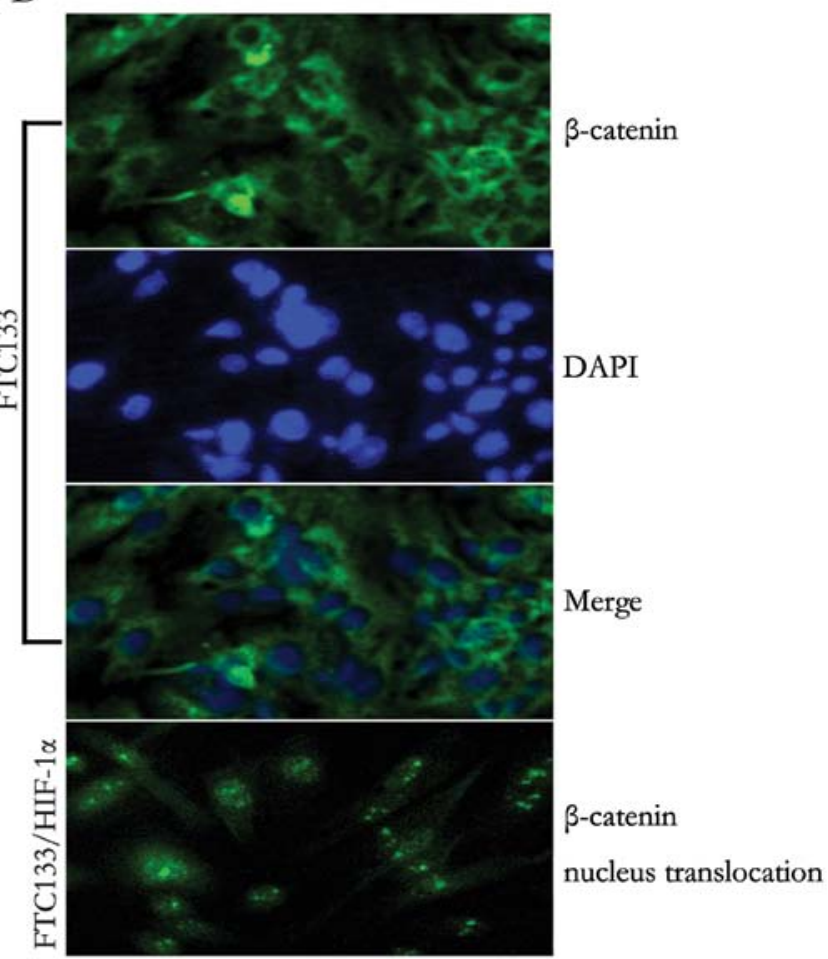

Figure 1. Overexpression of HIF-1 $\alpha$ induces EMT and $\beta$-catenin nucleus translocation. (A) HIF-1 $\alpha$-transfected FTC133 cells displayed specific functional expression of HIF-1 $\alpha$ as well as two downstream target proteins (Glut-1 and VEGF); in addition, in contrast to untransfected cells, FTC133/HIF-1 $\alpha$ cells were found with a decreased expression of epithelial markers E-cadherin and CK18, but increased Vimentin and Fibronectin. (B) FTC133 cells exhibited a strong positive expression of $\beta$-catenin in cytoplasma as shown in immunofluorescent staining. DAPI was used for nuclear DNA staining. HIF-1 $\alpha$ induction resulted in specific nucleus translocation of $\beta$-catenin from the cytoplasma in FTC133/HIF-1 $\alpha$ cells. FTC133/HIF-1 $\alpha$ cells showed typical fibroblast-like and spindle-shaped appearance, in contrast to FTC133 cells that possessed robust cellular junctions with typical 'cobblestone-shaped' and epithelial-like appearance.

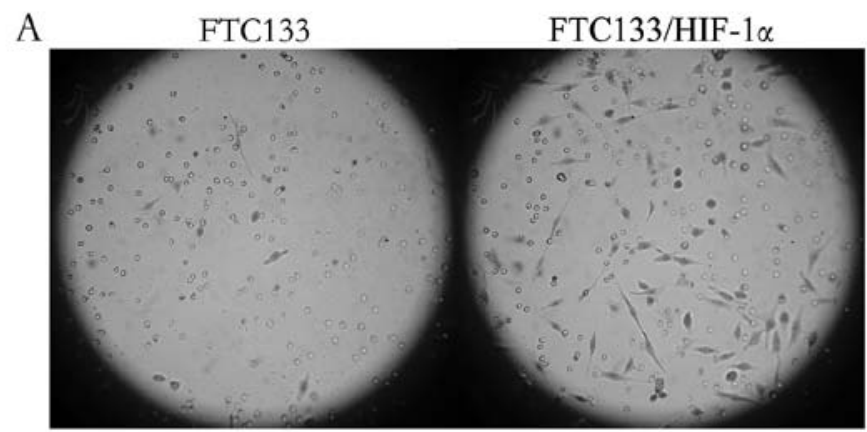

B

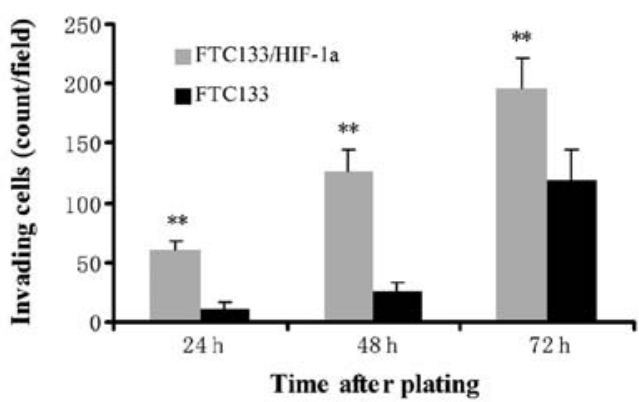

C

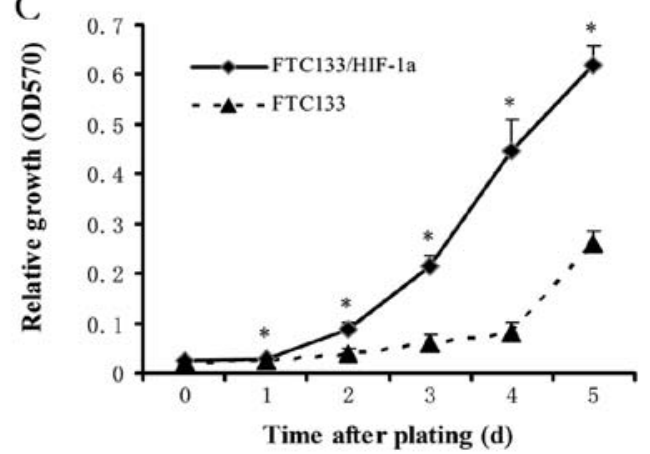

Figure 2. Cells that acquire an EMT phenotype show high invasiveness and proliferation in vitro. (A) Transwell assay indicated that after 24-h incubation, much more FTC133/HIF-1 $\alpha$ cells migrated through matrigel, compared with FTC133 cells. (B) At each time-point in invasion assay, FTC133/HIF-1 $\alpha$ showed increased gel invasion as compared to untransfected FTC133/HIF-1 $\alpha$ cells (all $\mathrm{p}<0.01$ ), which indicated that enhanced HIF-1 $\alpha$ expression contributes to increased invasiveness. (C) MTT proliferation assay displayed much higher proliferation in FTC133/HIF-1 $\alpha$ cells than untransfected FTC133 cells at each time-point (all p<0.05 except time-point of 0 day). ${ }^{*} \mathrm{p}<0.05$ and ${ }^{* *} \mathrm{p}<0.01$, when FTC133/HIF-1 $\alpha$ was compared with FTC133 cells. 
A
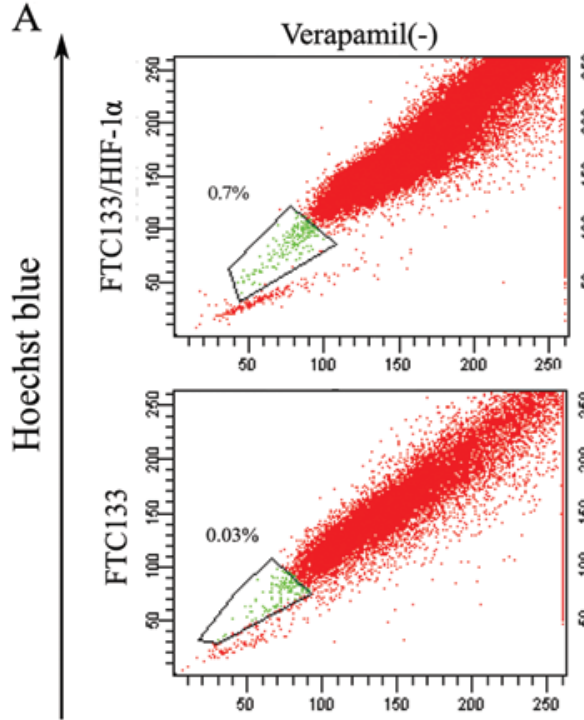
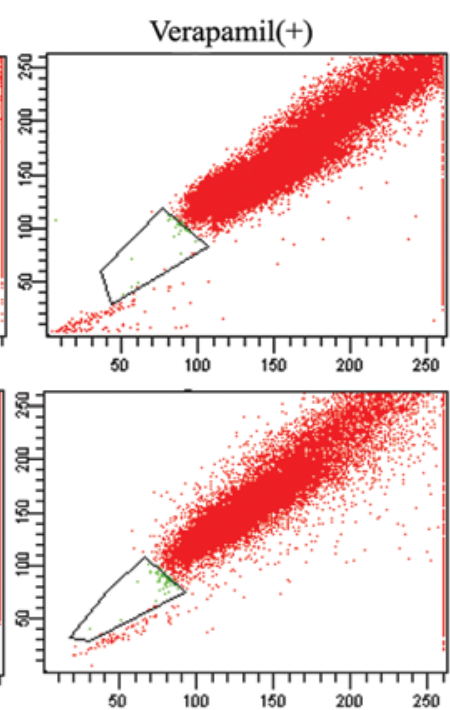

B

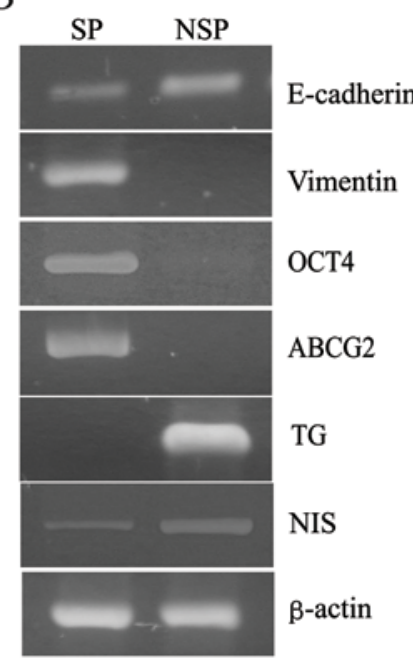

Hoechst red

Figure 3. EMT generates stem-like cells that express markers associated with both stemness and mesenchymal properties. To test the hypothesis that EMT program determines the CSC generation, stem-like side population cells were compared in FTC133 and FTC133/HIF-1 $\alpha$ cells. (A) Through HIF-1 $\alpha$ transfection, FTC133 cells acquired a much bigger side population in contrast to untransfected cells (SP, 0.7 vs. 0.03\%). (B) In contrast to NSP cells, the SP exhibited a strong reduction in the expression of E-cadherin and an increased expression of vimentin, and were further characterized with high expression of stem cell marker OCT4 and ABCG2, as well as low expression of thyroid differentiation factor thyroglobulin (TG) and sodium/iodide importer (NIS).
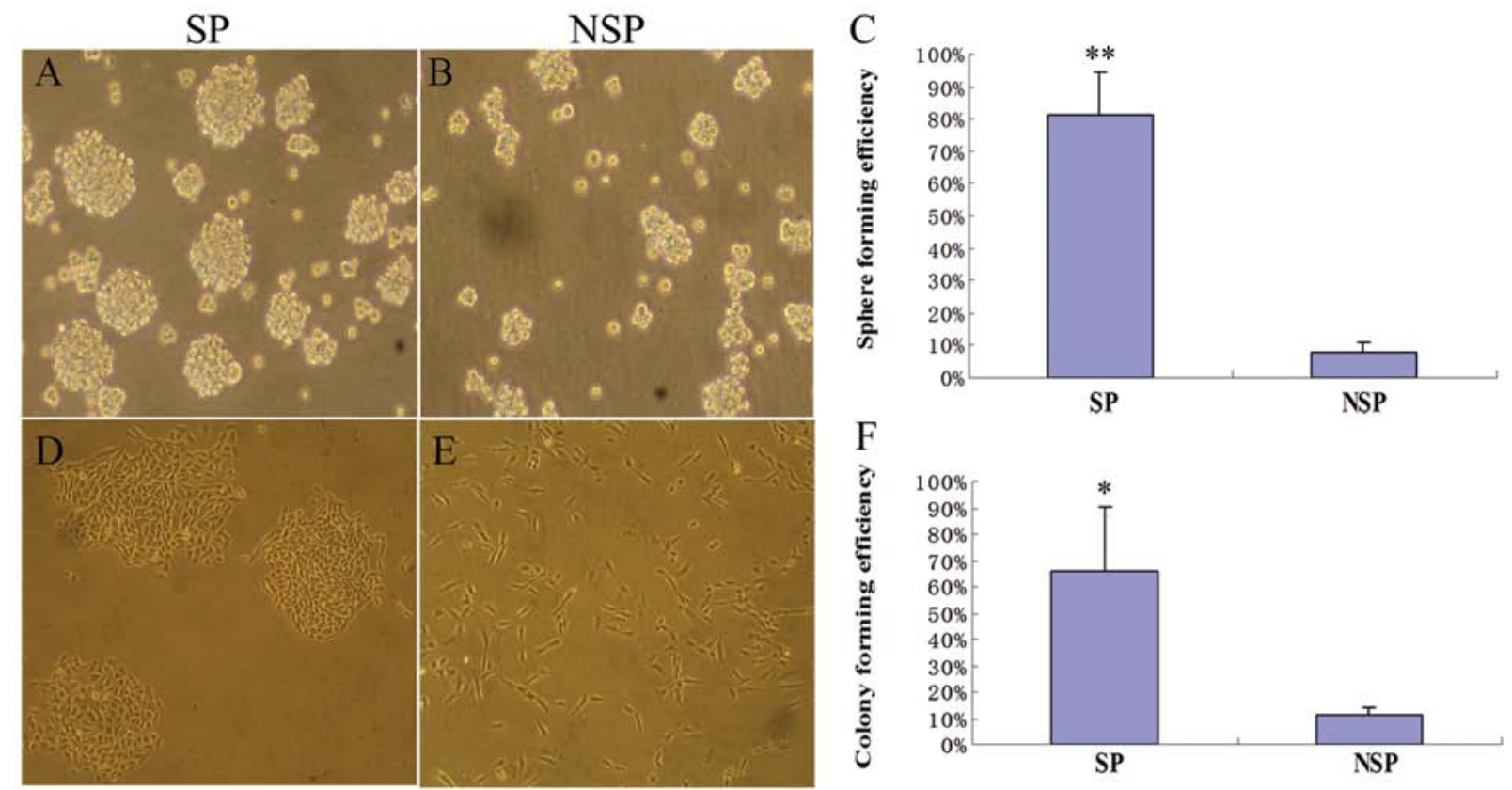

Figure 4. EMT-generated stem-like cells exhibit self-renewal and tumorigenic potential in vitro. Sphere growth culture was performed to test the self-renewal potential and a colony-forming assay synchronously served as an in vitro surrogate measure of tumorigenicity. SP cells from (A) FTC133/HIF-1 $\alpha$ cells formed much more tumor spheres than (B) the NSP cells, and showed (C) significantly higher sphere-forming efficiency ( $\mathrm{p}<0.01$ ). Most SP cells (D) could sustain the clone growth and form characteristic compact round colonies when plated in a very low density, whereas NSP cells always grew as more elongated or flattened cells in a scattered pattern with much fewer clones formed (E). (F) As shown in colony forming assay, SP cells showed 6-fold more colonies in soft agar, compared with the NSP cells $(\mathrm{p}<0.05)$. ${ }^{*} \mathrm{p}<0.05$ and $^{* *} \mathrm{p}<0.01$, when SP cells were compared with NSP cells.

stem cell marker expression and self-renewal potential $(14,16)$. Accordingly, in the present study, we used semi-quantitative RT-PCR to measure the expression of EMT-associated markers as well as stemness and differentiation-associated genes in SP sorted from FTC133/HIF-1 $\alpha$ cells. Specifically, we found, in contrast to NSP cells, the side population exhibited a strong reduction in the expression of E-cadherin and a significantly increased expression of vimentin (Fig. 3B). Furthermore, SP 
cells were characterized with high expression of stem cell transcription factor OCT4, and ATP-binding cassette transporter G2 (ABCG2), as well as low expression of thyroid differentiation factor thyroglobulin (TG) and sodium/iodide importer (NIS), as shown in Fig. 3B. These measurements provided further indication that the side population cells exist in a stem-like cell state that simultaneously closely resembles that of cells that have undergone EMT.

EMT-generated stem-like cells exhibit self-renewal and tumorigenic potential in vitro. Our previous studies $(14,16)$ have demonstrated that the ability to form thyroid-spheres in vitro depends on the presence of self-renewing stem cells within the thyroid tissue cell population or thyroid cancer cell lines. Therefore, a sphere growth culture was performed to test the self-renewal potential and the colony-forming assay synchronously served as an in vitro surrogate measure of tumorigenicity.

As anticipated, we observed that SP cells from FTC133/HIF-1 $\alpha$ cells formed at least 10-fold more tumor spheres than the NSP cells ( $p<0.01$, Fig. 4A-C). Moreover, most SP cells could sustain a clone growth and form characteristic compact round colonies when plated in a very low density, whereas NSP cells always grew as more elongated or flattened cells in a scattered pattern with much fewer clones formed (Fig. 4D-E). As shown in the colony forming assay, SP cells formed 6-fold more colonies in soft agar, compared with the NSP cells ( $p<0.05$, Fig. 4F). Based on these functional assays, we concluded that the cells generated by EMT acquired further two attributes of thyroid cancer stem cells.

\section{Discussion}

Thyroid cancer is the most prevalent endocrine neoplasia and accounts for approximately $1 \%$ of all carcinomas (26). Among these, anaplastic thyroid carcinoma is considered to be one of the most rapidly growing lethal neoplasms in humans. Emerging evidence suggest that the acquisition of EMT is strongly associated with cancer cell invasion and tumor metastasis. Recently, studies have shown that cells with EMT phenotype share characteristics that are consistent with the signatures of cancer stem-like cells, which are associated with tumor recurrence and drug resistant phenotype and contribute to the demise of patients diagnosed with cancer $(22,27,28)$. Understanding the molecular and cellular changes may generate novel targets that can overcome the aforementioned issues and reduce mortality.

In the current study, we made three novel observations. Firstly, we found that forced-expression of HIF-1 $\alpha$ in epithelialtype thyroid cancer cells induced cellular morphological changes that were consistent with the acquisition of EMT phenotype as characterized by the loss of expression of epithelial markers and the gain or increased expression of mesenchymal markers. Furthermore, these EMT-induced cells exhibited specific mesenchymal properties and were highly invasive and proliferative. Most importantly, the induction of EMT conferred the cells an increased clonogenic and sphere-forming capacity, the characteristics that are known to be associated with cancer stem-like cell characteristics.

EMT-inducers, such as transforming growth factor- $\beta$ (TGF- $\beta$ ) or hypoxia, trigger changes in gene expression by complex signaling pathways. A basic mechanism involved in progression of EMT is upregulation of the mesenchymal marker vimentin and downregulation of the epithelial marker E-cadherin, the main transmembrane adhesion molecule responsible for cell-to-cell interactions and tissue organization in epithelial cells $(29,30)$. In our study, FTC133 cells were identified as epithelial-type cells with specific protein expression. When overexpressed with HIF-1 $\alpha$, these cells (FTC133/HIF-1 $\alpha$ ) adopted mesenchymal cell properties, and presented fibroblastoid phenotypes, had a more extended and spindle-like shape. These significant morphological changes combined with specific protein analysis of a number of canonical EMT markers demonstrated that the epithelial tumor cells underwent EMT, in which high invasiveness and proliferation were identified with functional analysis as invasion and MTT assays. These findings in FTC133 cells are consistent with our prior study that showed HIF-1 $\alpha$ has a crucial role in EMT and is associated with an increased invasive ability in human prostate cancers (25). Previous mounting evidence suggests hypoxia as an important driving force and master regulator for the multistep process of metastasis $(31,32)$. In addition, the activated HIFs may induce the expression of numerous gene products such as induced pluripotency-associated transcription factors (Oct-3/4, Nanog and Sox-2), glycolysis- and epithelial-mesenchymal transition (EMT) programme-associated molecules, including CXC chemokine receptor 4 (CXCR4), snail and twist, microRNAs and angiogenic factors such as vascular endothelial growth factor (VEGF). Moreover, several studies have suggested that Wnt/ $\beta$-catenin signaling pathway plays an important role in epithelial-mesenchymal transition (33-36). Also in the current study, we found that the HIF-1 $\alpha$ inducted EMT program is accompanied by activation of $\mathrm{Wnt} / \beta$-catenin signal pathway and nucleus translocation of the adherens junction component $\beta$-catenin. All these gene products in turn can play critical roles for high self-renewal ability, survival, altered energy metabolism, invasion and metastases of cancer cells, angiogenic switch and treatment resistance. Consequently, the targeting of hypoxic inducible factor signaling network and altered metabolic pathways in cancer- and metastasisinitiating cells and their progenies as well as their supporting host cells represents new promising strategies to simultaneously eradicate the total mass of cancer cells and improve the efficacy of current therapies against aggressive and metastatic cancers and prevent disease relapse.

Self-renewal potential, which is one of the hallmarks of CSCs, has been demonstrated in CSCs through their ability to form colonies or spheres $(37,38)$. In this study, we have shown that the induction of EMT in human thyroid cancer cells yields cells with much higher invasiveness and proliferation. We have confirmed, that such cells are greatly enriched in tumorinitiating cells with markedly high CFE and sphere-formation capability, as well as specific stemness signatures of OCT4 and ABCG2. Therefore, our findings suggest a close correlation between EMT program and the emergence of CSC-like phenotype in thyroid cancer cells.

In previous studies, some scholars have described a 'parent-child relationship' between EMT and CSC based on experiments that revealed some common molecular mechanisms shared by the EMT development and CSC generation. Using a mammary tumor progression model, Morel et al 
showed that acquisition of stemness characteristics in epithelial cells can be driven by EMT induction following the activation of the Ras-MAPK pathway (39). Mani et al also reported that the breast cancer cells that had undergone EMT triggered by various factors are rich source of stemlike cancer cells and the induction of EMT in differentiated immortalized human mammary epithelial cells led to the acquisition of $\mathrm{CD}_{4} 4^{+} / \mathrm{CD} 24^{-}$stem cell phenotype (20). These data further support our findings that EMT program represents the driving force for the generation of cancer stem-like cells in thyroid cancer.

Collectively, our previous and current studies revealed, follicular thyroid cancer cells that acquired EMT phenotype as anaplastic thyroid cancer cells, shared cellular and molecular characteristics of stem cells or cancer stem-like cells, most importantly, we firstly reported the increased cancer stem cell content directly correlates with EMT induction, and concluded that, the emergence of CSC-like phenotype occurs as a result of EMT in epithelial thyroid cancer cells. Activated Wnt/ $\beta$-catenin signals by hypoxic stimulus played a critical role in linking EMT phenotype with stem cell signatures by activating EMT program. Therefore, in future studies we may emphasize elimination of stem-like cells by undermining the hypoxia microenviroment or hypoxic inducible factor signaling network, or further reversing EMT phenotypic cells to MET phenotype in anaplastic thyroid cancer. We firmly believe that strategies by which one could either reverse the EMT to MET phenotype or could selectively kill EMT-phenotypic cells or cancer stem-like cells that are 'Root cause' of tumor development and recurrence, could become a novel approach for the prevention of tumor progression and/or treatment of anaplastic thyroid cancer and its metastasis for which newer therapies are urgently needed.

\section{Acknowledgements}

The authors are grateful to Professor Michael Derwahl (Berlin, Germany) for the gift of of FTC133 cell line and for his excellent technical guidance. This study was supported by National Natural Science Foundation of China (fund nos. 30901725, 30700968 and 30800416).

\section{References}

1. Are $\mathrm{C}$ and Shaha AR: Anaplastic thyroid carcinoma: biology, pathogenesis, prognostic factors and treatment approaches. Ann Surg Oncol 13: 453-464, 2006.

2. Jordan CT, Guzman ML and Noble M: Cancer stem cells. N Engl J Med 355: 1253-1261, 2006.

3. Ward RJ and Dirks PB: Cancer stem cells: at the headwaters of tumor development. Annu Rev Pathol 2: 175-189, 2007.

4. Kondo T, Setoguchi T and Taga T: Persistence of a small subpopulation of cancer stem-like cells in the C6 glioma cell line. Proc Natl Acad Sci USA 101: 781-786, 2004.

5. Hirschmann-Jax C, Foster AE, Wulf GG, Nuchtern JG, Jax TW, Gobel U, Goodell MA and Brenner MK: A distinct 'side population' of cells with high drug efflux capacity in human tumor cells. Proc Natl Acad Sci USA 101: 1422814233, 2004

6. Singh SK, Clarke ID, Terasaki M, Bonn VE, Hawkins C, Squire J and Dirks PB: Identification of a cancer stem cell in human brain tumors. Cancer Re 63: 5821-5828, 2003.

7. Hemmati HD, Nakano I, Lazareff JA, Masterman-Smith M, Geschwind DH, Bronner-Fraser $M$ and Kornblum HI: Cancerous stem cells can arise from pediatric brain tumors. Proc Natl Acad Sci USA 100: 15178-15183, 2003.
8. Ignatova TN, Kukekov VG, Laywell ED, Suslov ON, Vrionis FD and Steindler DA: Human cortical glial tumors contain neural stem-like cells expressing astroglial and neuronal markers in vitro. Glia 39: 193-206, 2002.

9. Bonnet D and Dick JE: Human acute myeloid leukemia is organized as a hierarchy that originates from a primitive hematopoietic cell. Nat Med 3: 730-737, 1997.

10. Friedman S, Lu M, Schultz A, Thomas D and Lin RY: CD133+ anaplastic thyroid cancer cells initiate tumors in immunodeficient mice and are regulated by thyrotropin. PLoS One 4: e5395, 2009.

11. Zito G, Richiusa P, Bommarito A, Carissimi E, Russo L, Coppola A, Zerilli M, Rodolico V, Criscimanna A, Amato M, Pizzolanti G, Galluzzo A and Giordano C: In vitro identification and characterization of CD133(pos) cancer stem-like cells in anaplastic thyroid carcinoma cell lines. PLoS One 3: e3544, 2008.

12. Thomas D, Friedman S and Lin RY: Thyroid stem cells: lessons from normal development and thyroid cancer. Endocr Relat Cancer 15: 51-58, 2008.

13. Thomas T, Nowka K, Lan L and Derwahl M: Expression of endoderm stem cell markers: evidence for the presence of adult stem cells in human thyroid glands. Thyroid 16: 537-544, 2006

14. Lan L, Cui D, Nowka K and Derwahl M: Stem cells derived from goiters in adults form spheres in response to intense growth stimulation and require thyrotropin for differentiation into thyrocytes. J Clin Endocrinol Metab 92: 3681-3688, 2007.

15. Fierabracci A, Puglisi MA, Giuliani L, Mattarocci S and Gallinella-Muzi M: Identification of an adult stem/progenitor cell-like population in the human thyroid. J Endocrinol 198: 471-487, 2008.

16. Zheng XQ, Cui D, Xu SH, Brabant G and Dereahl M: Doxorubicin fails to eradicate cancer stem cells derived from anaplastic thyroid carcinoma cells: characterization of resistant cells. Int J Oncol 37: 307-315, 2010.

17. Mitsutake N, Iwao A, Nagai K, Namba H, Ohtsuru A, Saenko V and Yamashita S: Characterization of side population in thyroid cancer cell lines: cancer stem-like cells are enriched partly but not exclusively. Endocrinology 148: 1797-1803, 2007.

18. Takano $\mathrm{T}$ and Amino N: Fetal cell carcinogenesis: a new hypothesis for better understanding of thyroid carcinoma. Thyroid 15: 432-438, 2005.

19. Thiery JP: Epithelial-mesenchymal transitions in tumour progression. Nat Rev Cancer 2: 442-454, 2002.

20. Mani SA, Guo W, Liao MJ, Eaton EN, Ayyanan A, Zhou AY, Brooks M, Reinhard F, Zhang CC, Shipitsin M, Campbell LL, Polyak K, Brisken C, Yang J and Weinberg RA: The epithelial mesenchymal transition generates cells with properties of stem cells. Cell 133: 704-715, 2008.

21. Raimondi C, Gianni W, Cortesi E and Gazzaniga P: Cancer stem cells and epithelial-mesenchymal transition: revisiting minimal residual disease. Current Cancer Drug Targets 10: 496-508, 2010.

22. Hollier BG, Evans K and Mani SA: The epithelial-to-mesenchymal transition and cancer stem cells: a coalition against cancer therapies. J Mammary Gland Biol Neoplasia 14: 29-43, 2009.

23. Hayashida T, Jinno H, Kitagawa Y and Kitajima M: Cooperation of cancer stem cell properties and epithelial-mesenchymal transition in the establishment of breast cancer metastasis. J Oncol 2011: 591427, 2011.

24. Goretzki PE, Frilling A, Simon D and Roeher HD: Growth regulation of normal thyroids and thyroid tumors in man. Recent Results Cancer Res 118: 48-63, 1990.

25. Luo Y, He DL, Ning L, Shen SL, Li L, Li X, Zhau HE and Chung LW: Over-expression of hypoxia-inducible factor-1alpha increases the invasive potency of LNCaP cells in vitro. BJU Int 98: 1315-1319, 2006.

26. Hundahl SA, Fleming ID, Fremgen AM and Menck HR: A National Cancer Data Base report on 53,856 cases of thyroid carcinoma treated in the U.S., 1985-1995. Cancer 83: 2638-2648, 1998.

27. Kong D, Banerjee S, Ahmad A, Li Y, Wang Z, Sethi S and Sarkar FH: Epithelial to mesenchymal transition is mechanistically linked with stem cell signatures in prostate cancer cells. PLoS One 5: e12445, 2010.

28. Klarmann GJ, Hurt EM, Mathews LA, Zhang X, Duhagon MA, Mistree T, Thomas SB and Farrar WL: Invasive prostate cancer cells are tumor initiating cells that have a stem cell-like genomic signature. Clin Exp Metastasis 26: 433-446, 2009. 
29. Huber MA, Kraut N and Beug H: Molecular requirements for epithelial mesenchymal transition during tumor progression. Curr Opin Cell Biol 17: 548-558, 2005.

30. Salnikov AV, Liu L, Platen M, Gladkich J, Salnikova O, Ryschich E, Mattern J, Moldenhauer G, Werner J, Schemmer P Buechler MW and Herr I: Hypoxia induces EMT in low and highly aggressive pancreatic tumor cells but only cells with cancer stem cell characteristics acquire pronounced migratory potential. PLoS One 7: e46391, 2012.

31. Lu X and Kang YB: Hypoxia and hypoxia-inducible factors: master regulators of metastasis. Clin Cancer Res 16: 5928-5935, 2010.

32. Mimeault M and Batra SK: Hypoxia-inducing factors as master regulators of stemness properties and altered metabolism of cancer- and metastasis-initiating cells. J Cell Mol Med 17: 30-54, 2013.

33. Nelson WJ and Nusse R: Convergence of Wnt, beta-catenin, and cadherin pathways. Science 303: 1483-1487, 2004.

34. Kim K, Lu Z and Hay ED: Direct evidence for a role of beta-catenin/ LEF-1 signaling pathway in induction of EMT. Cell Biol Int 26: 463-476, 2002.
35. Medici D, Hay ED and Olsen BR: Snail and Slug promote epithelialmesenchymal transition through beta-catenin-Tcell factor-4- dependent expression of transforming growth factor-beta3. Mol Biol Cell 19: 4875-4887, 2008.

36. Yang L, Lin C and Liu ZR: P68 RNA helicase mediates PDGF-induced epithelial mesenchymal transition by displacing Axin from beta-catenin. Cell 127: 139-155, 2006.

37. Clarke MF, Dick JE, Dirks PB, Eaves CJ, Jamieson $\mathrm{CH}$, Jones DL, Visvader J, Weissman IL and Wahl GM: Cancer stem cells - perspectives on current status and future directions: AACR Workshop on cancer stem cells. Cancer Res 66: 9339-9344, 2006.

38. Hurt EM, Chan K, Serrat MA, Thomas SB, Veenstra TD and Farrar WL: Identification of vitronectin as an extrinsic inducer of cancer stem celldifferentiation and tumor formation. Stem Cell 28: 390-398, 2010.

39. Morel AP, Lièvre M, Thomas C, Hinkal G, Ansieau S and Puisieux A: Generation of breast cancer stem cells through epithelial-mesenchymal transition. PLoS One 3: e2888, 2008. 